\title{
The cyclooxygenases
}

\section{NV Chandrasekharan and Daniel L Simmons}

Address: Department of Chemistry and Biochemistry, Brigham Young University, Provo, UT 84602, USA.

Correspondence: NV Chandrasekharan.E-mail: nchandra@chem.byu.edu

Published: 27 August 2004

Genome Biology 2004, 5:24I

The electronic version of this article is the complete one and can be

found online at http://genomebiology.com/2004/5/9/24 I

(C) 2004 BioMed Central Ltd

\begin{abstract}
Summary
Cyclooxygenases (COXs) catalyze the rate-limiting step in the production of prostaglandins, bioactive compounds involved in processes such as fever and sensitivity to pain, and are the target of aspirin-like drugs. COX genes have been cloned from coral, tunicates and vertebrates, and in all the phyla where they are found, there are two genes encoding two COX isoenzymes; it is unclear whether these genes arose from an early single duplication event or from multiple independent duplications in evolution. The intron-exon arrangement of COX genes is completely conserved in vertebrates and mostly conserved in all species. Exon boundaries largely define the four functional domains of the encoded protein: the amino-terminal hydrophobic signal peptide, the dimerization domain, the membrane-binding domain, and the catalytic domain. The catalytic domain of each enzyme contains distinct peroxidase and cyclooxygenase active sites; COXs are classified as members of the myeloperoxidase family. All COXs are homodimers and monotopic membrane proteins (inserted into only one leaflet of the membrane), and they appear to be targeted to the lumenal membrane of the endoplasmic reticulum, where they are $\mathrm{N}$-glycosylated. In mammals, the two COX genes encode a constitutive isoenzyme (COX-I) and an inducible isoenzyme (COX-2); both are of significant pharmacological importance.
\end{abstract}

\section{Gene organization and evolutionary history}

Cyclooxygenases (COXs), also known as prostaglandin $\mathrm{H}$ synthases or prostaglandin endoperoxide synthases (E.C. 1.14.99.1), are fatty-acid oxygenases of the myeloperoxidase superfamily that are most closely related to the pathogeninducible oxidases and linoleate diol synthases of plants and fungi [1]. The purification of COX-1 (then called simply COX) from sheep [2] and bovine [3] seminal vesicles in 1976 led to the cloning of the COX-1 gene in 1988 [4-6]. For many years, it was thought that the constitutively active COX-1 protein was the only cyclooxygenase in eukaryotic cells, but in 1991 a second, inducible enzyme was identified through studies of cell division; this second enzyme is now called COX-2 $[7,8]$. The structure of the human COX-1 and $C O X-2$ genes are shown in Figure 1a, and the properties of COX-1 and COX-2 and the genes encoding them are compared in Table 1.
All vertebrates investigated, including cartilaginous fishes, bony fishes, birds, and mammals, have two COX genes: one encoding the constitutive COX-1 and another the inducible COX-2. COX-1 and COX-2 share approximately 60-65\% amino-acid identity with each other; COX-1 orthologs (without the signal peptide) share approximately 70-95\% amino-acid identity across vertebrate species and COX-2 orthologs share 70-90\%. Additionally, coral (of the phylum Cnidaria) and sea squirt (ascidian) each have two COX genes, which may have arisen from gene-duplication events independent from those that produced vertebrate $C O X-1$ and $C O X-2$ [9]. It is clear that the vertebrate, coral and ascidian $C O X$ genes all descend from a common ancestor.

Intron-exon junctions are highly conserved in all species, with a few notable exceptions: the vertebrate $C O X-1$ genes contain an extra intron (intron 1), and the ascidian and coral 
(a)

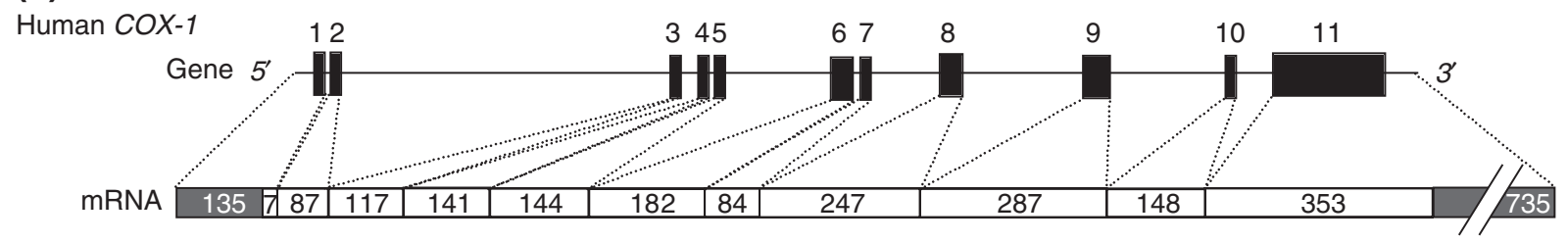

Human COX-2

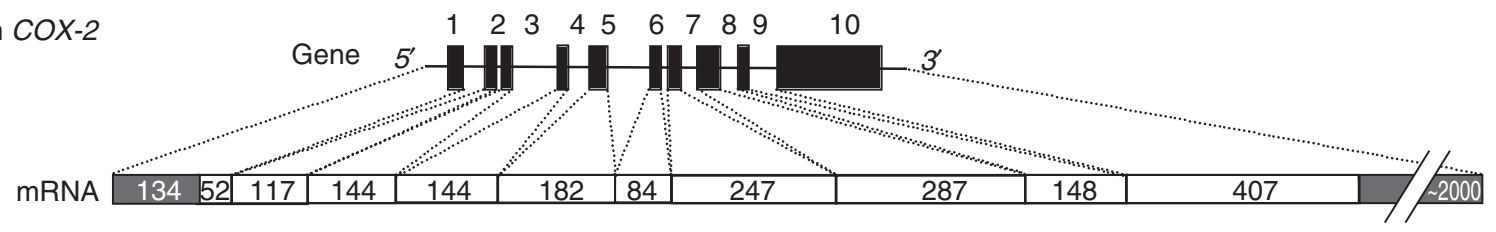

(b)

mRNA

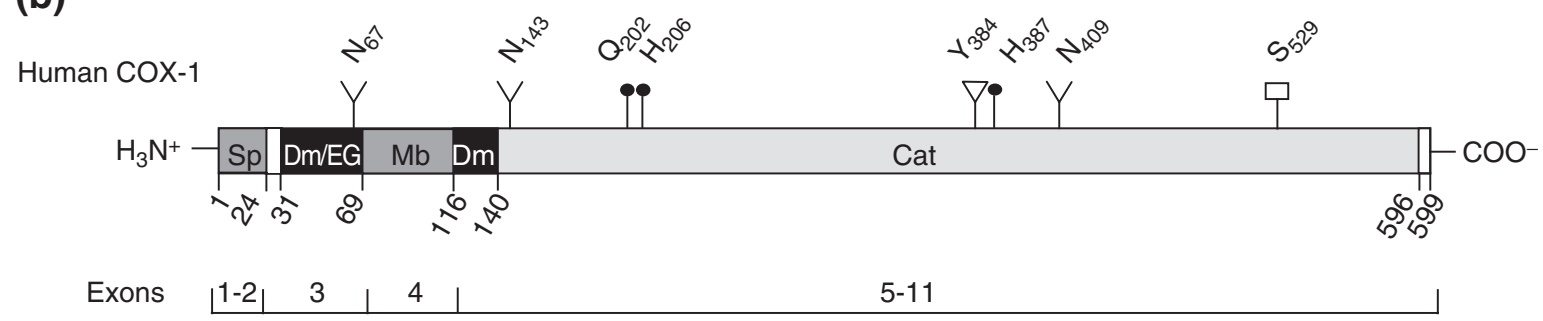

Human COX-2

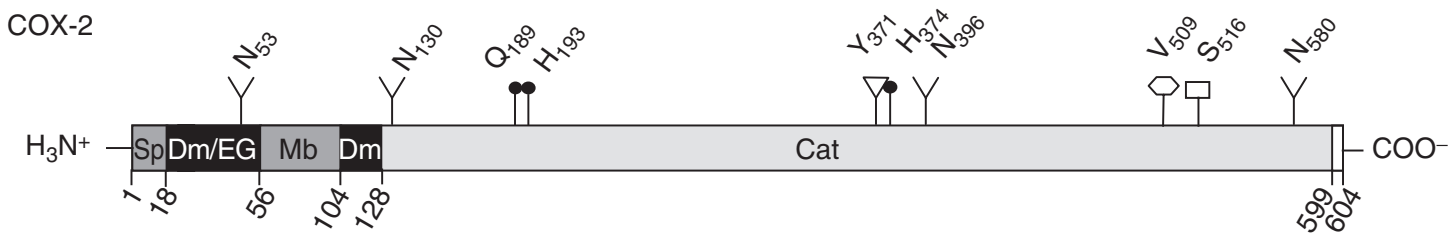

Exons

\begin{tabular}{|l|l|}
1 & 2 \\
\end{tabular}

$4-10$

\begin{tabular}{|c|c|c|c|c|}
\hline$Y$ & Glycosylation site & Y & $\begin{array}{l}\text { Tyrosine at } \\
\text { active site }\end{array}$ & $\begin{array}{l}\text { Valine in COX-2 } \\
\text { active site }\end{array}$ \\
\hline 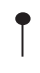 & $\begin{array}{l}\text { Residue involved in } \\
\text { heme coordination }\end{array}$ & ๆ & $\begin{array}{l}\text { Serine acetylated } \\
\text { by aspirin }\end{array}$ & \\
\hline
\end{tabular}

Figure I

Primary structures of COX genes and COX proteins. (a) Schematic representation of human COX-I and COX-2 genes and the mRNAs they encode (shown as white bars below the genes). Black boxes in the genes and white boxes in the mRNAs denote exons; numbers above each gene are exon numbers while numbers within the white boxes indicate the size of each exon in nucleotides; single lines in the genes indicate introns and untranslated regions of first and last exons (the latter being shown as gray boxes in the mRNAs). Adapted from [10]. (b) Schematic representation of human COX proteins (all known vertebrate proteins have the same general arrangement). Numbers denote amino-acid residues; the exons encoding each domain are shown on bars below the proteins; important residues are indicated as shown in the key (and with letters in the single-letter amino-acid code, with a subscript number indicating the residue number). Sp, signal peptide; Dm, dimerization domain; EG; epidermal growth factor domain; Mb, membranebinding domain; Cat, catalytic domain.

genes have extra introns or lack some exons in the regions that encode exons 6,7 or 11 in vertebrate $C O X-1$ [9]. The exon structures of $C O X$ genes largely reflect the domains encoded by the proteins (Figure 1b). The structure of human cyclooxygenase genes and their expression and regulation have been reviewed elsewhere [10].
COX genes have not been found in insects, unicellular organisms, or plants, although prostaglandins, their products, have been found in some of these organisms [11]. Recently, an enzyme that catalyzes the synthesis of prostaglandin $\mathrm{E}_{2}$ from arachidonic acid (the substrate of COXs) was cloned from the protozoan Entamoeba histolytica. This enzyme shows no 
Table I

\begin{tabular}{|c|c|c|}
\hline Property & COX-I & $\operatorname{cox}-2$ \\
\hline Chromosomal location of gene & $9 q 32-q 33.3$ & Iq25.2-25.3 \\
\hline Copy number of gene & Single & Single \\
\hline Gene size & About $22 \mathrm{~kb}$ & About $8 \mathrm{~kb}$ \\
\hline Number of exons & 11 & 10 \\
\hline Number of introns & 10 & 9 \\
\hline Length of primary mRNA & $2.8 \mathrm{~kb}$ & $4.5 \mathrm{~kb}$ \\
\hline Length of differentially polyadenylated variants & $4.5 \mathrm{~kb}, 5.2 \mathrm{~kb}$ & $4.0 \mathrm{~kb}, 2.8 \mathrm{~kb}$ \\
\hline Lengths of splice variants & See $[13,34]$ & See $[13,34]$ \\
\hline Length of coding region & I,797 nucleotides & I,8I 2 nucleotides \\
\hline \multicolumn{3}{|l|}{ Putative transcription regulatory elements found in: } \\
\hline promoter & TATA-less & TATA box \\
\hline $5^{\prime}$ upstream region* & $\begin{array}{l}\text { AP-2, GATA-I, NF-IL6, NFKB, PEA-3, } \\
\text { SP-I, SSRE }\end{array}$ & $\begin{array}{l}\text { AP-2, C/EBP, CRE, GATA-I, GRE, NF-IL6, NFKB, } \\
\text { PEA-3, SP-I }\end{array}$ \\
\hline $3^{\prime}$ untranslated region & & AUUUA repeats \\
\hline Expression & Constitutive & Inducible (by cytokines, growth factors and so on $[10,35]$ ) \\
\hline Length of protein (with signal peptide) & 599 amino acids & 604 amino acids \\
\hline Length of mature protein (without signal peptide) & 576 amino acids & 581 amino acids \\
\hline Number of glycosylation sites & 3 & 3-4 (variable) \\
\hline Cofactors & Heme & Heme \\
\hline Substrates & Arachidonic acid & Arachidonic acid and others \\
\hline Quaternary structure & Homodimer & Homodimer \\
\hline Subcellular location & Endoplasmic reticulum & Endoplasmic reticulum and nuclear envelope \\
\hline
\end{tabular}

Information from [10,13,35]. *Abbreviations: CRE, cyclic AMP response element; GATA-I, binding site containing GATA sequence bound by the GATA I transcription factor; GRE, glucocorticoid-response element; SSRE, shear-stress response element; other abbreviations denote the transcription factors bound by the regulatory elements shown: AP-2, activator protein 2; C/EBP, CCAAT/enhancer-binding protein; NF-IL6, nuclear factor for interleukin 6; NFKB, nuclear factor $\kappa B$; PEA-3, polyoma enhancer activator; SP-I, transcription factor SP-I.

clear structural similarity to COXs, suggesting that alternative evolutionary paths to prostaglandin synthesis have evolved in some organisms [12].

\section{Characteristic structural features}

COXs are all close to 600 amino acids in size and have a similar primary structure [13,14] (Figure 1b). The crystal structure of sheep COX-1 (minus the post-translationally cleaved signal peptide), was obtained in 1994 [15]; human and mouse COXs have since been crystallized and show strikingly similar features $[16,17]$. After the signal peptide, the amino terminus of the protein contains a single epidermal growth factor (EGF) module with conserved disulfide bonds that functions as a dimerization domain. This is followed by a series of four amphipathic helices that anchors the protein to one leaflet of the membrane. This 'monotopic' type of insertion into a membrane has been found only in this enzyme and a few other proteins such as squalene cyclase and $S$-mandelate dehydrogenase $[18,19]$. The remainder of the protein consists of the catalytic domain, which has two distinct cyclooxygenase and peroxidase active sites.

COXs are highly conserved, and few significant differences are seen in the dimerization, membrane-binding and catalytic domains between COXs from different species. The aminoterminal hydrophobic signal peptides differ significantly in length between species. In the case of two splice variants of canine COX -1 , the signal peptide has been found not to be cleaved from the enzyme when expressed in insect cells [20].

The catalytic domain contains conserved alpha-helical structures and a heme-binding motif shared with other peroxidases [15]. COXs are glycosylated on asparagine in all organisms. One $N$-glycosylation site (Asn143, using the numbering of human COX-1) is absolutely conserved, and other sites are shifted only slightly in different homologs. For example, Asn410 in sheep COX-1 (orthologous to 
Asn409 in human COX-1), found to be essential for folding [21], is shifted to Asn394 in coral COXs. The cyclooxygenase active site is a narrow tunnel, approximately $8 \AA$ wide and $25 \AA$ long, that opens in the membrane-binding domain (Figure 2). This site accepts the arachidonic acid that is liberated from the membrane by cellular phospholipases. Amino acids lining this site are largely hydrophobic and serve to 'solvate' the hydrophobic substrate into the site [22]. Exceptions to this hydrophobicity are Arg119, Tyr384 and Ser529 (numbered according to the human COX-1 enzyme sequence). Arg119 coordinates the carboxyl group of arachidonic acid by a salt bridge or hydrogen bond; Ser529 coordinates the geometry of attack in the complex bis-dioxygenation reaction performed; and Tyr384 forms a critical tyrosyl radical that initiates the cyclooxygenase reaction by abstraction of hydrogen from arachidonic acid (see Mechanism section). Non-steroidal anti-inflammatory drugs (NSAIDs) competitively inhibit the cyclooxygenase active site; an exception is the NSAID aspirin, which covalently modifies the enzyme by acetylating Ser529. In contrast to the cyclooxygenase active site, the peroxidase site is a solvent accessible cleft located on the surface of the enzyme furthest from the membrane (Figure 2).

\section{Localization and function}

COX-1 is ubiquitously and constitutively expressed in mammalian tissues and cells, whereas COX-2 is highly inducible and is generally present in mammalian tissues at very low levels, unless increased by one of many types of stimuli such as cytokines and growth factors.

Both COXs are largely located on the lumenal side of the endoplasmic reticulum (ER) membrane and the nuclear envelope, although they have also been detected in some situations in lipid bodies, mitochondria, filamentous structures, vesicles and in the nucleus [23-26]. The lumen of the ER is important for both the structure and function of COXs: its oxidative potential allows formation of the disulfide bonds of the enzymes, and $N$-linked glycosylation - which occurs in the ER - appears to be necessary for proper protein folding [21]. Moreover, the final product of COXs, prostaglandin $\mathrm{H}_{2}$, is sufficiently non-polar to diffuse through the membrane of the ER to isomerases located on the cytosolic surface of the ER or in the cytosol (Figures 2, 3). Lipid bodies may provide a similar environment, but the role of COXs in the nucleus is unknown.

Both classes of COX are bifunctional enzymes with two distinct catalytic activities: cyclooxygenase (or bis-dioxygenase) activity and peroxidase activity (Figure 3a). The primary products of COXs were first detected in human seminal fluid by clinicians studying uterine contraction [27]. Thought to be the product of the prostate gland, these highly potent bioactive compounds were given the name prostaglandins. They are synthesized in virtually all tissues in vertebrates, however,

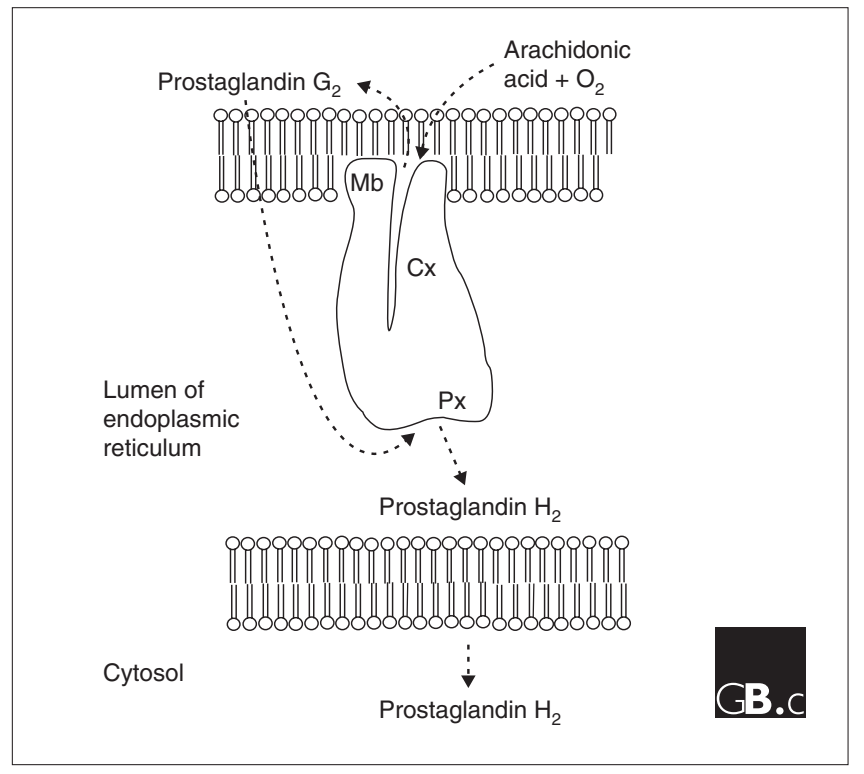

Figure 2

Cross-section of a cyclooxygenase monomer in the lumen of the endoplasmic reticulum, showing the two distinct catalytic sites. $C_{x}$, cyclooxygenase catalytic site; Mb, membrane-binding domain; Px, peroxidase catalytic site.

and some organisms that lack prostate glands, such as corals, also synthesize prostaglandins. Thus, in many respects the term prostaglandin is a misnomer. Initially, the enzyme activity that synthesized prostaglandins was frequently called prostaglandin synthetase, but because it does not require ATP it is now called prostaglandin G/H synthase to fit the nomenclature convention. It is more popularly known as cyclooxygenase, a name that only partially describes the enzyme since it refers to only one of its two enzymatic activities.

Prostaglandin isomers - including thromboxane and prostaglandins $\mathrm{D}_{2}, \mathrm{E}_{2}, \mathrm{~F}_{2 \alpha}$, and $\mathrm{I}_{2}$ (prostacyclin; Figure $3 \mathrm{~b}$ ) function in numerous physiological and pathophysiological processes, such as pyresis (fever), algesia (sensitivity to pain), inflammation, thrombosis, parturition, mitogenesis, vasodilation and vasoconstriction, ovulation, and renal function. Prostaglandin isomers act upon G-protein-coupled receptors [28], and there are multiple receptors for some isoforms (such as prostaglandin $\mathrm{E}_{2}$ ). Prostaglandins are short-lived in vivo (with half-lives of seconds to minutes), and act in an autocrine or a paracrine rather than an endocrine fashion. COX-1 was first studied in tissue and cell homogenates, and in this context was shown by Vane [29] to be the inhibitory target of NSAIDs.

\section{Mechanism}

The cyclooxygenase activity of COXs oxygenates arachidonic acid to produce prostaglandin $\mathrm{G}_{2}$, a cyclopentane hydroperoxy endoperoxide; the peroxidase activity of COXs then reduces 


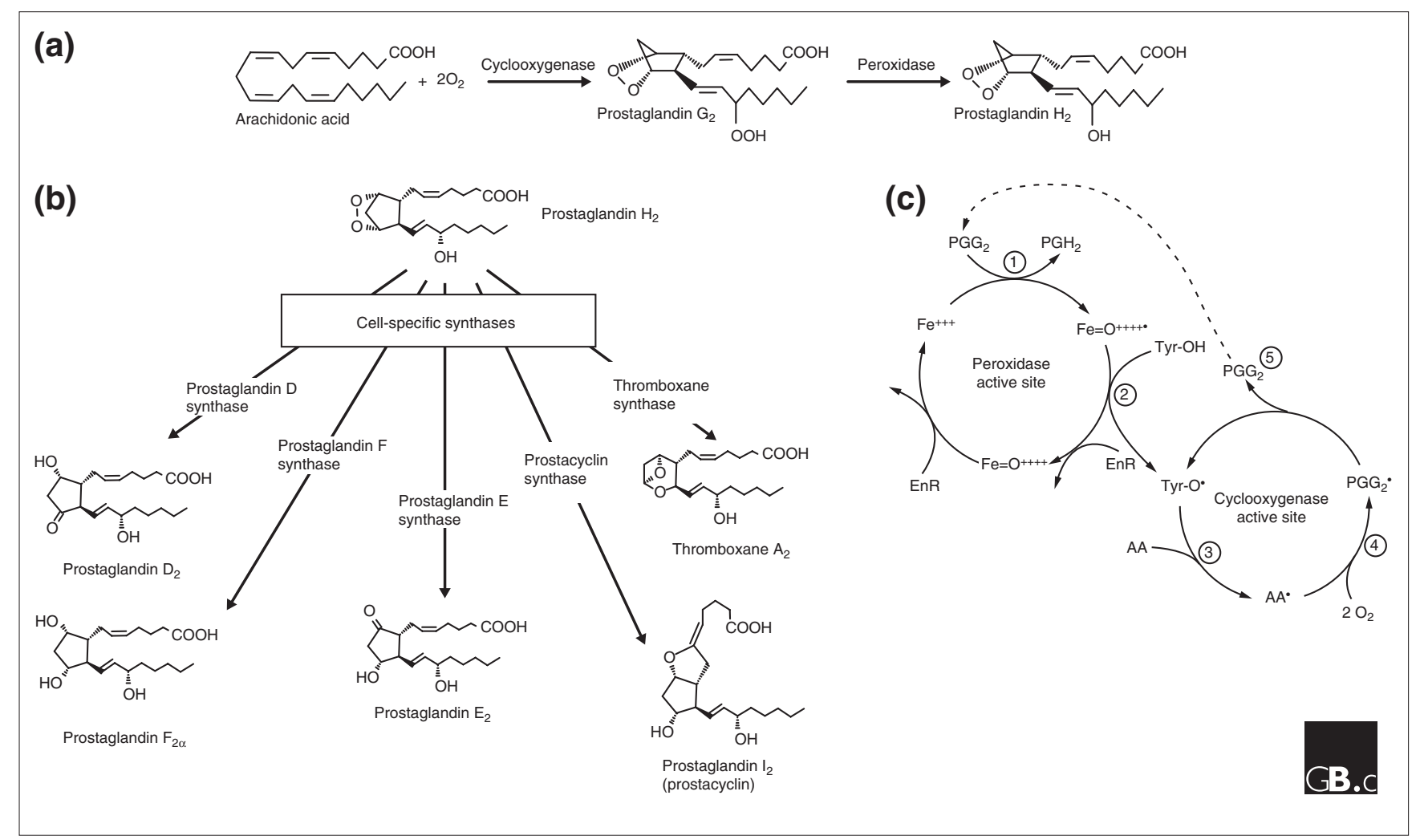

Figure 3

Production of prostaglandins by COXs. (a) The two reactions performed by cyclooxygenases: the conversion of arachidonic acid to prostaglandin $\mathrm{G}_{2}$ by the cyclooxygenase activity and the conversion of prostaglandin $\mathrm{G}_{2}$ to prostaglandin $\mathrm{H}_{2}$ by the peroxidase activity. (b) The cell-specific synthases that are involved in the conversion of prostaglandin $\mathrm{H}_{2}$ to the five principal prostaglandins. (c) The reaction mechanism of COX-I. (I) First, a ferryl-oxo (FelV) protoporphyrin radical in the heme in the peroxidase active site is produced when endogenous oxidant(s) oxidizes ferric heme (Felli) to ferryl-oxo (FelV) protoporphyrin radical through a two-electron oxidation. (2) The Tyr384 residue in the cyclooxygenase active site is activated, through a singleelectron reduction reaction with the FelV protoporphyrin radical, to produce a tyrosyl radical. In the first step of the oxygenation process (3), the I3-pro(S) hydrogen of arachidonic acid in the COX site is abstracted by the tyrosyl radical to produce the arachidonyl radical. (4) This is followed by the reaction of the arachidonyl radical with two molecules of oxygen, to yield prostaglandin $G_{2}$. (5) Prostaglandin $G_{2}$ then diffuses (dotted line) to the peroxidase active site and is reduced to prostaglandin $\mathrm{H}_{2}$ by the peroxidase activity (I). AA, arachidonic acid; EnR, an endogenous reductant; Fe ${ }^{+++}$, ferric heme; $\mathrm{Fe}=\mathrm{O}^{++++}$, Ferryl-oxo FelV porphyrin radical; Tyr-OH, active site tyrosine; Tyr-O; tyrosyl radical.

this to prostaglandin $\mathrm{H}_{2}$ (Figure $3 \mathrm{a}$ ). The two reactions are functionally interconnected (see below and Figure $3 \mathrm{c}$ ). A branch-chain reaction mechanism for COX, indicating that the two reaction cycles are coupled, was first proposed by Ruf and colleagues [30]. The mechanism by which arachidonic acid is converted to prostaglandin $\mathrm{H}_{2}$ has been the subject of excellent reviews [31,32]. The newly synthesized COX enzyme needs to be activated at Tyr384 (in human COX-1; Tyr371 in human COX-2) to produce a tyrosyl radical; this activation involves the heme in the peroxidase site (see Figure $3 \mathrm{~b}$ ). The tyrosyl radical converts arachidonic acid to an arachidonyl radical, which reacts with two molecules of oxygen to yield prostaglandin $\mathrm{G}_{2}$. This then diffuses to the peroxidase site and is reduced to prostaglandin $\mathrm{H}_{2}$ by the peroxidase activity. The cyclooxygenase activity is dependent on heme oxidation - that is, on the peroxidase activity - but continuous peroxidase activity is not necessary for cyclooxygenase activity, as the tyrosyl radical is regenerated in each catalytic cycle (Figure 3c). Prostaglandin $\mathrm{H}_{2}$ is the root prostaglandin from which prostaglandin isomers such as thromboxane and prostacyclin are made by downstream synthases, via isomerization and oxidation or reduction reactions (Figure 3b). Cyclooxygenases have short catalytic life spans (frequently 1-2 minutes at $\mathrm{V}_{\max }$ in vitro) because the enzyme is autoinactivated. The mechanism of autoinactivation is unknown, but reactive tyrosyl radicals may cause internal protein modification.

\section{Frontiers}

The exact distinct functions of COX-1 and COX-2 are still being unraveled [33]. There is increasing evidence for the involvement of COXs in the development and progression of cancer, Alzheimer's disease and other pathophysiological states. Development of therapeutic and diagnostic tools to treat these diseases is being actively investigated. Moreover, variants of cyclooxygenase derived from alternative splicing 
have been reported (reviewed in [13,34]). Elucidation of the roles played by these variants could provide greater insight into the roles of COXs in physiology and disease.

\section{Acknowledgements}

This work was supported by National Institute of Health grant AR 46688 and Merck, USA. We wish to thank K.L.T. Roos, D. Melville and C. Gurney for helping us in numerous ways.

\section{References}

I. Daiyasu H, Toh H: Molecular evolution of the myeloperoxidase family. J Mol Evol 2000, 5 I:433-445.

An evolutionary analysis of the myeloperoxidases.

2. Hemler M, Lands WEM, Smith WL: Purification of the cyclooxygenase that forms prostaglandins: demonstration of two forms of iron in the holoenzyme. J Biol Chem 1976, 25 I:55755579.

The first isolation and purification of cyclooxygenase from sheep seminal vesicles.

3. Miyamoto T, Ogino N, Yamamoto S, Hayaishi O: Purification of prostaglandin endoperoxide synthetase from bovine vesicular gland microsomes. J Biol Chem 1976, 25 I:2629-2636.

The first isolation and purification of cyclooxygenase enzyme from bovine seminal vesicles.

4. Yokoyama C, Tanabe $T$ : Cloning of human gene encoding prostaglandin endoperoxide synthase and primary structure of the enzyme. Biochem Biophys Res Commun 1989, 165:888-894. The cloning of human cyclooxygenase-I (COX-I).

5. Merlie JP, Fagan D, Mudd J, Needleman P: Isolation and characterization of the complementary DNA for sheep seminal vesicle prostaglandin endoperoxide synthase (cyclooxygenase). J Biol Chem 1988, 263:3550-3553.

The cloning of the first cyclooxygenase gene from sheep.

6. DeWitt DL, Smith WL: Primary structure of prostaglandin G/H synthase from sheep vesicular gland determined from the complementary DNA sequence. Proc Natl Acad Sci USA 1988, 85: $1412-1416$.

The cloning of the first cyclooxygenase gene from sheep.

7. Xie W, Chipman JG, Robertson DL, Erikson RL, Simmons DL: Expression of a mitogen-responsive gene encoding prostaglandin synthase is regulated by mRNA splicing. Proc Natl Acad Sci USA 199I, 88:2692-2696.

The first report on the cloning and characterization of a second isozyme of cyclooxygenase (COX-2).

8. Kujubu DA, Fletcher BS, Varnum BC, Lim RW, Herschman HR: TISI0, a phorbol ester tumor promoter-inducible mRNA from Swiss 3T3 cells, encodes a novel prostaglandin synthase/cyclooxygenase homologue. J Biol Chem I991, 266: I286612872.

Cloning and characterization of a second isozyme of cyclooxygenase (COX-2).

9. Jarving R, Jarving I, Kurg R, Brash AR and Samel N: On the evolutionary origin of cyclooxygenase (COX) isozymes: characterization of marine invertebrate COX genes points to independent duplication events in vertebrate and invertebrate lineages. J Biol Chem 2004, 279: I3624-I 3633.

An evolutionary analysis of invertebrate cyclooxygenases.

10. Tanabe $\mathrm{T}$, Tohnai $\mathrm{N}$ : Cyclooxygenase isozymes and their gene structures and expression. Prostaglandins Other Lipid Mediat 2002, 68-69:95-II4.

A review on the gene structures and expression of COX-I and COX-2.

II. Bundy GL: Nonmammalian sources of eicosanoids. Adv Prostaglandin Thromboxane Leukot Res 1985, 14:229-262. A review on prostaglandins from nonmammalian sources.

12. Dey I, Keller K, Belley A, Chadee K: Identification and characterization of a cyclooxygenase-like enzyme from Entamoeba histolytica. Proc Natl Acad Sci USA 2003, 100: 1356 I-13566.

The cloning of a prostaglandin-producing enzyme unrelated to the cyclooxygenases.

13. Simmons DL, Botting RM, Hla T: Cyclooxygenase isozymes: the biology of prostaglandin synthesis and inhibition. Pharmacol Rev, in press.
A review on the biology of prostaglandin synthesis and inhibition by non-steroidal anti-inflammatory drugs (NSAIDs).

14. Garavito RM, Malkowski MG, DeWitt DL: The structures of prostaglandin endoperoxide $H$ synthases- $I$ and $\mathbf{- 2}$. Prostaglandins Other Lipid Mediat 2002, 68-69:129-I52.

A review on the structure of cyclooxygenases.

15. Picot D, Loll P, Garavito M: The X-ray crystal structure of the membrane protein prostaglandin $\mathbf{H}_{2}$ synthase-I. Nature 1994, 367:243-249.

A landmark study elucidating the three dimensional structure of sheep COX-1.

16. Luong C, Miller A, Barnett J, Chow J, Ramesha C, Browner MF: Flexibility of the NSAID binding site in the structure of human cyclooxygenase-2. Nat Struct Biol 1996, 3:927-933.

The first report on the crystal structure of human COX-2.

17. Kurumbail RG, Stevens AM, Gierse JK, McDonald J], Stegeman RA Pak JY, Gildehaus D, Miyashiro JM, Penning TD, Seibert K, et al:: Structural basis for selective inhibition of cyclooxygenase-2 by anti-inflammatory agents. Nature 1996, 384:644-648. The crystal structure of murine COX-2.

18. Wendt KU, Poralla K, Schulz GE: Structure and function of a squalene cyclase. Science 1997, 277:1788-1789.

Describes the crystal structure of squalene cyclase, which has membrane-binding properties similar to those of cyclooxygenase.

19. Sukumar N, Xu Y, Gatti DL, Mitra B, Mathews FS: Structure of an active soluble mutant of the membrane-associated (S)-mandelate dehydrogenase. Biochemistry 200I, 40:9870-9878.

Describes the crystal structure of $\mathbf{S}$-mandelate dehydrogenase, which has membrane-binding properties similar to those of cyclooxygenase.

20. Chandrasekharan NV, Dai H, Roos KLT, Evanson NK, Tomsik J, Elton TS, Simmons DL: COX-3, a cyclooxygenase-I variant inhibited by acetaminophen and other analgesic/antipyretic drugs: cloning, structure, and expression. Proc Natl Acad Sci USA 2002, 99:|3926-|393|.

The cloning and characterization of canine COX-I variants.

21. Otto JC, DeWitt DL, Smith WL: N-glycosylation of prostaglandin endoperoxide synthase- $\mathrm{I}$ and $\mathbf{- 2}$ and their orientations in the endoplasmic reticulum. J Biol Chem 1993, 268: | 8234- 18242.

Describes the role of glycosylation in cyclooxygenases.

22. Thuresson ED, Lakkides KM, Rieke C], Sun Y, Wingerd BA, Micielli R, Mulichack AM, Malkowski MG, Garavito RM, Smith WL: Prostaglandin endoperoxide $H$ synthase- $I$ : the function of cyclooxygenase active site residues in the binding, positioning, and oxygenation of arachidonic acid. J Biol Chem 200I, 276: $10347-10358$.

A mutational analysis of the cyclooxygenase active site.

23. Bozza PT, Yu W, Penrose JF, Morgan ES, Dvorak AM, Weller PF: Eosinophil lipid bodies: specific, inducible intracellular sites for enhanced eicosanoid formation. J Exp Med 1997, 186:909920.

Cyclooxygenases in lipid bodies.

24. Liou JY, Deng WG, Gilroy DW, Shyue SK, Wu KK: Colocalization and interaction of cyclooxygenase-I with caveolin-I in human fibroblasts. J Biol Chem 200I, 276:34975-34982. Cyclooxygenases in vesicles.

25. Coffey RJ, Hawkey CJ, Damstrup L, Graves-Deal R, Daniel VC Dempsey PJ, Chimery R, Kirkland SC, DuBois RN, Jetton TL, Morrow JD: Epidermal growth factor receptor activation induces nuclear targeting of cyclooxygenase-2, basolateral release of prostaglandins, and mitogenesis in polarizing colon cancer cells. Proc Natl Acad Sci USA 1997, 94:657-662. The nuclear localization of COX-2.

26. Liou JY, Shyue SK, Tsai MJ, Chung CL, Chu KY, Wu KK: Colocalization of prostacyclin synthase with prostaglandin $\mathbf{H}$ synthase-I (PGHS-I) but not phorbol ester-induced PGHS-2 in cultured endothelial cells. J Biol Chem 2000, 275:I53|4-I5320.

Demonstration of the colocalization of cyclooxygenase with filamentous structures.

27. Goldblatt MW: A depressor substance in seminal fluid. J Soc Chem Ind 1933, 52:1056-1057.

The first detection of the products of COXs in human seminal fluid.

28. Narumiya S, Sugimoto Y, Ushikubi F: Prostanoid receptors: structures properties and functions. Physiological Rev 1999, 79: $1193-1226$.

A review on prostanoid receptors. 
29. Vane JR: Inhibition of prostaglandin synthesis as a mechanism of action for aspirin-like drugs. Nature 1971, 23 I:232-235. The first report indicating that the target for aspirin-like drugs is cyclooxygenase.

30. Dietz R, Nastainczyk W, Ruf HH: Higher oxidation states of prostaglandin H synthase. Rapid electronic spectroscopy detected two spectral intermediates during the peroxidase reaction with prostaglandin G2. Eur J Biochem 1988, I71:321328.

The first paper to propose a branch chain mechanism for cyclooxygenase catalysis.

3I. Rouzer CA, Marnett LJ: Mechanism of free radical oxygenation of polyunsaturated fatty acids by cyclooxygenases. Chem Rev 2003, 103:2239-2304.

A review on the reaction mechanism of cyclooxygenase.

32. van der Donk WA, Tsai A-L, Kulmacz RJ: The cyclooxygenase reaction mechanism. Biochemistry 2002, 4 I: |545I-I5457.

A review on the reaction mechanism of cyclooxygenase.

33. Loftin CD, Tiano HF, Langenbach R: Phenotypes of the COXdeficient mice indicate physiological and pathophysiological roles for COX-I and COX-2. Prostaglandins Other Lipid Mediat 2002, 68-69:|77-|85.

Determination of the roles of COX-1 and COX-2 using COX-1-1. COX-2-t, and COX-1-1- COX-2-r- mice.

34. Simmons DL: Variants of cyclooxygenase-I and their roles in medicine. Thrombosis Res 2003, I I 0:265-268.

A review on variants of COX-I.

35. Smith WL, De Witt DL, Garavito RM: Cyclooxygenases: structural, cellular and molecular biology. Annu Rev Biochem 2000, 69: $145-182$

A review on cyclooxygenases. 